\title{
Predictive value of vascular endothelial growth factor polymorphisms on the clinical outcome of renal cell carcinoma patients
}

\author{
NAN MA ${ }^{1}$, LI-WEI LI ${ }^{2}$ and JING-LIANG CHENG ${ }^{3}$ \\ Departments of ${ }^{1}$ Interventional Radiography, ${ }^{2}$ Anesthesia and ${ }^{3}$ MRI, The First Affiliated Hospital, Zhengzhou University, \\ Zhengzhou, Henan 4500052, P.R. China
}

Received December 22, 2013; Accepted September 8, 2014

DOI: $10.3892 / 01.2014 .2798$

\begin{abstract}
A cohort study was conducted to investigate the association between vascular endothelial growth factor (VEGF) polymorphisms $-2578 \mathrm{C} / \mathrm{A},-1154 \mathrm{G} / \mathrm{A}$ and $-634 \mathrm{C} / \mathrm{G}$ and the clinical outcome of renal cell carcinoma (RCC), as well as the interaction of VEGF polymorphisms with tumor stage, metastasis and size. A total of $310 \mathrm{RCC}$ patients were recruited from the First Affiliated Hospital of Zhengzhou University (Zhengzhou, China) between January 2006 and December 2007, and were followed up until December 2012. The association between the three single nucleotide polymorphisms and the overall survival of RCC patients was estimated using Cox's proportional hazard regression model. The median follow-up duration was 34.7 months and 74 of the RCC patients succumbed due to cancer during the follow-up period. The frequency of the VEGF -2578 AA genotype was significantly higher in patients classed as tumor stages III-IV (odds ratio [OR], 0.47; 95\% confidence interval [CI], 0.24-0.95) and larger tumors (longest diameter, $>4$ cm; OR, 0.44; 95\% CI, 0.22-0.89). Furthermore, the frequency of VEGF -634 GG was significantly higher in patients with larger tumors (longest diameter, $>4 \mathrm{~cm}$; OR, 0.68; 95\% CI,0.48-0.97). The VEGF-2578 AA genotype was correlated with a 2.96-fold increase in the risk of RCC-associated mortality and was associated with a five-year survival rate of $\sim 25 \%$. Therefore, the present study identified that the VEGF -2578C/A polymorphism may be associated with the prognosis of RCC patients, and may interact with the tumor stage and size.
\end{abstract}

\section{Introduction}

Renal cell carcinoma (RCC) is a prominent disease, with $\sim 57,760$ new cases and $\sim 12,980$ mortalities reported

Correspondence to: Mr. Jing-Liang Cheng, Department of MRI, The First Affiliated Hospital, Zhengzhou University, 1 Jian She Dong Road, Zhengzhou, Henan 4500052, P.R. China

E-mail: manan_zzu@163.com

Key words: renal cell carcinomas, vascular endothelial growth factor, clinical outcome, polymorphism worldwide in 2009 (1). Although the majority of patients exhibiting early-stage RCC can be treated surgically, recurrence with distant metastases was observed upon diagnosis in $25-50 \%$ of RCC patients and the five-year survival rate was $<20 \%(2,3)$. Patients that were diagnosed with the same stage of renal cancer and that received similar treatment to early-stage RCC patients demonstrated a different prognosis, indicating that hereditary factors may contribute to the prognosis of RCC (4,5). Furthermore, previous studies have reported that vascular endothelial growth factors (VEGFs), and platelet-derived growth factors and their receptors may have a role in promoting the pathogenesis of $\operatorname{RCC}(6,7)$.

The VEGF gene is a potent endothelial cell mitogen, which consists of eight exons (8). It has been hypothesized that 30 types of single nucleotide polymorphism (SNP) exist in the VEGF gene (8). Three common SNPs, VEGF -2578C/A, $-1154 \mathrm{G} / \mathrm{A}$ and $-634 \mathrm{C} / \mathrm{G}$, have been widely investigated and identified to be associated with VEGF protein production (9). Furthermore, VEGF -2578C/A, -1154G/A and $-634 \mathrm{C} / \mathrm{G}$ have been associated with the risk or the prognosis of various diseases, such as breast cancer, pancreatic adenocarcinoma, oral cancer and Alzheimer's disease (10-13).

A previous study indicated that VEGF is overexpressed in RCC tissue when compared with healthy renal tissue (14). Furthermore, therapeutic targeting of VEGF has demonstrated clinical efficacy in the treatment of RCC $(15,16)$; thus, VEGF polymorphisms may be associated with disease progression and prognosis in RCC patients. However, three studies reported inconsistent results regarding the association between VEGF polymorphisms and progression or prognosis of RCC (17-19). Therefore, the current report presents a cohort study investigating the association between VEGF polymorphisms $-2578 \mathrm{C} / \mathrm{A},-1154 \mathrm{G} / \mathrm{A}$ and $-634 \mathrm{C} / \mathrm{G}$, and the clinical outcome of RCC patients, as well as the interaction of the VEGF polymorphisms with tumor stage, metastasis and size.

\section{Patients and methods}

Patients. Patients that were diagnosed with RCC between January 2006 and November 2007 were enrolled in the present study from the First Affiliated Hospital of Zhengzhou University. Patients with a history of pregnancy, malignancy, 
chemotherapy or radiotherapy were excluded from the present study. All of the biopsy samples were obtained via radical or partial nephrectomy. The RCC tumor stage was determined according to the American Joint Committee on Cancer tumor-node-metastasis staging system (20). The patients in the study were followed up until November 2012, however, six patients were lost to follow-up. Baseline characteristics of all of the patients were obtained using a self-designed questionnaire and medical records. Written informed consent was obtained from all patients and this study was approved by the ethics committee of The First Affiliated Hospital of Zhengzhou University (Zhengzhou, China).

Polymerase chain reaction (PCR). All of the patients provided a 5-ml peripheral venous blood sample after consenting to participate in the study. Genomic DNA was extracted using a TIANamp Blood DNA kit (Tiangen Biotech Co., Ltd., Beijing, China) and DNA dissolved in water, according to the manufacturer's instructions. The presence of VEGF -2578C/A, $-1154 \mathrm{G} / \mathrm{A}$ and $-634 \mathrm{C} / \mathrm{G}$ was determined using PCR combined with a restriction fragment length polymorphism assay (Applied Biosystems, Foster City, CA, USA). The primers and probes for VEGF $-2578 \mathrm{C} / \mathrm{A},-1154 \mathrm{G} / \mathrm{A}$ and $-634 \mathrm{C} / \mathrm{G}$ were designed using Assay Design 3.1 software (Sequenom Inc., San Diego, CA, USA). The PCR reaction was performed in a $25-\mu 1$ reaction solution with $25 \mathrm{mM} \mathrm{MgCl}$, each primer and $2 \mathrm{mM}$ deoxynucleotide triphosphates, $1 \mathrm{mmol} / 1 \mathrm{MgCl}_{2}, 1.25$ units Taq polymerase (Takara Biotechnology Co., Ltd., Dalian, China) and $0.5 \mu 15$ X PCR buffer (Takara Biotechnology Co., Ltd.). The DNA was amplified at $95^{\circ} \mathrm{C}$ for $5 \mathrm{sec}$, subjected to 40 cycles at $92^{\circ} \mathrm{C}$ for $40 \mathrm{sec}$ and elongated at $60^{\circ} \mathrm{C}$ for $40 \mathrm{sec}$.

Statistical analysis. All analyses were conducted using SPSS version 16.0 software (SPSS Inc., Chicago,IL, USA). Continuous variables are expressed as the mean \pm standard deviation and categorical variables are expressed as frequencies (percentages). The $\chi^{2}$ test was used to compare the genotype frequencies between the patients and the controls. The primary end point was five-year survival, which was calculated as the time period from diagnosis to mortality (from any cause), or the last known date that the patient was alive. Survival differences were compared using the log-rank test and multivariate analysis of survival was conducted using Cox's proportional hazard regression analysis (with hazard ratios [HR] and 95\% confidence intervals [CI]) to identify independent prognostic variables. Survival distributions were estimated using the Kaplan-Meier method and assessed using the log-rank test. Two-tailed P-values of $<0.05$ were considered to indicate a statistically significant difference.

\section{Results}

Patient characteristics and outcomes. A total of 336 patients with RCC were invited to participate in the present study; 310 patients consented, resulting in a participation rate of $92.26 \%$. The demographic and clinical characteristics of the patients are presented in Table I. The cohort consisted of 206 males (66.45\%) and 104 females (33.55\%) with a median age of 61.5 years (range, 27.2-81.4 years) upon initial diagnosis. Of the 310 patients, $91.61 \%$ exhibited clear cell RCC, $60.32 \%$ exhibited stage I-II cancer, $61.29 \%$ had a small tumor (longest diameter,
Table I. Univariate analysis of the demographic and clinic characteristics of 310 renal cell carcinoma patients (age, 61.5 years; range, 27.2-81.4 years).

\begin{tabular}{ccc}
\hline Variable & $\begin{array}{c}\text { Patients, } \\
\mathrm{n}(\%)\end{array}$ & $\begin{array}{c}\text { Overall survival } \\
\text { period, months }\end{array}$
\end{tabular}

Gender

$\begin{array}{lll}\text { Male } & 206(66.45) & 33.5 \\ \text { Female } & 104(33.55) & 34.6\end{array}$

Tumor histology

Non-clear cell

Clear cell

$284(91.61)$

35.7

Tumor stage

$\begin{array}{lll}\text { I-II } & 187(60.32) & 38.6 \\ \text { III-IV } & 123(39.68) & 27.4\end{array}$

Tumor size, $\mathrm{cm}$

$\begin{array}{lrr}>4 & 120(38.71) & 28.7 \\ \leq 4 & 190(61.29) & 36.4 \\ \text { Metastasis } & & \\ \text { No } & 67(21.61) & 35.5 \\ \text { Yes } & 243(78.39) & 29.2\end{array}$

Tumor size refers to the longest diameter of the tumor. Tumor stage was determined according to the American Joint Committee on Cancer tumor-node-metastasis staging system (20).

$\leq 4 \mathrm{~cm}$ ), and $78.39 \%$ presented with lymph node or distant metastases. Patients exhibiting clear cell RCC, stage I-II cancer, a small tumor (longest diameter, $\leq 4 \mathrm{~cm}$ ) and no metastasis were associated with a longer OS period.

VEGF genotypes and tumor characteristics. The genotype distributions of VEGF -2578C/A, -1154G/A and $-634 \mathrm{C} / \mathrm{G}$ demonstrated Hardy-Weinberg equilibrium. Conditional regression analysis identified that the VEGF -2578 AA genotype was significantly more frequent in stage III-IV patients (odds ratio [OR], 0.47; 95\% CI, 0.24-0.95) and patients with larger tumors (longest diameter, $>4 \mathrm{~cm}$; OR $=0.44 ; 95 \% \mathrm{CI}, 0.22-0.89$ ) when compared with the $-2578 \mathrm{CC}$ genotype (Table II). Furthermore, the VEGF -634 GG genotype was significantly more frequent in patients with a large tumor (longest diameter, $>4 \mathrm{~cm}$ ) when compared with the -634 CC genotype (OR, 0.68; 95\% CI, 0.48-0.97).

Multivariate analysis. The association between the VEGF genotype and survival with RCC is demonstrated in Table III. The median duration of the follow-up was 33.8 months (range, 2-69 months). Among the 310 patients, 174 patients succumbed due to cancer during the follow-up period, providing a five-year survival rate of $43.87 \%$. The VEGF -2578 AA genotype was significantly associated with poor OS (adjusted HR, 2.96; 95\% CI, 1.40-6.53), and the five-year survival rate of patients exhibiting the AA genotype was $25.0 \%$ (Table III). However, the VEGF -1154G/A and -634C/G polymorphisms were not significantly associated with the OS of RCC patients. 


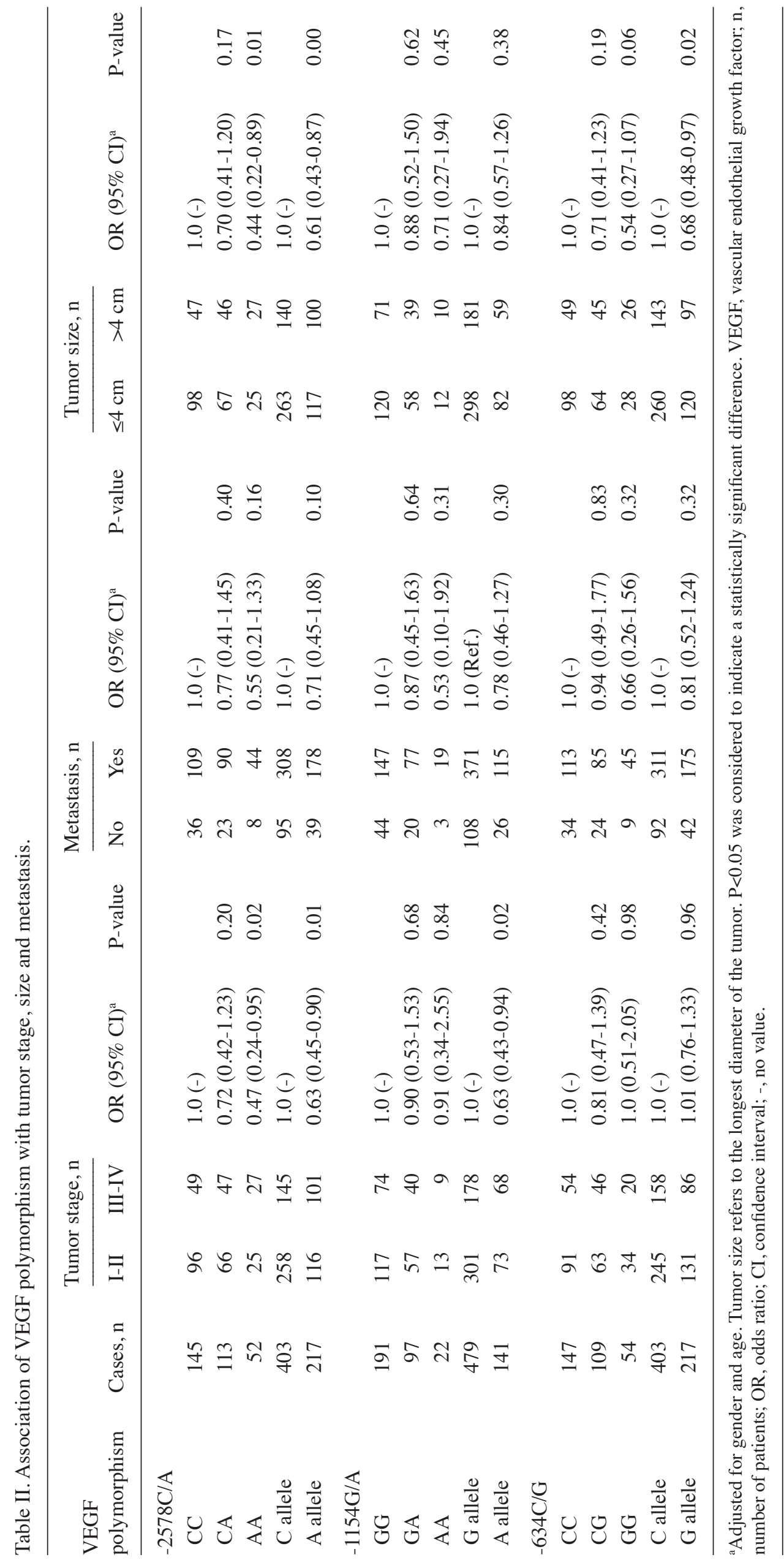


Table III. Cox's proportional hazard regression analysis of VEGF polymorphisms on the survival of renal cell carcinoma patients.

\begin{tabular}{|c|c|c|c|c|c|}
\hline $\begin{array}{l}\text { VEGF } \\
\text { polymorphism }\end{array}$ & Cases, $\mathrm{n}$ & Mortalities, n & $\begin{array}{c}\text { Five-year } \\
\text { survival rate, } \%\end{array}$ & $\begin{array}{l}\text { Hazard ratio } \\
(95 \% \mathrm{CI})^{\mathrm{a}}\end{array}$ & P-value \\
\hline \multicolumn{6}{|l|}{$-2578 \mathrm{C} / \mathrm{A}$} \\
\hline $\mathrm{CC}$ & 145 & 73 & 49.7 & $1.0(-)$ & \\
\hline $\mathrm{CA}$ & 113 & 62 & 45.1 & $1.20(0.71-2.02)$ & 0.47 \\
\hline $\mathrm{AA}$ & 52 & 39 & 25.0 & $2.96(1.40-6.53)$ & 0.00 \\
\hline $\mathrm{C}$ allele & 403 & 208 & 48.5 & $1.0(-)$ & \\
\hline A allele & 217 & 140 & 35.3 & $1.73(1.21-2.46)$ & 0.00 \\
\hline \multicolumn{6}{|l|}{$-1154 \mathrm{G} / \mathrm{A}$} \\
\hline GG & 191 & 104 & 45.5 & $1.0(-)$ & \\
\hline GA & 97 & 55 & 43.3 & $1.10(0.65-1.85)$ & 0.72 \\
\hline AA & 22 & 15 & 31.8 & $1.79(0.65-5.43)$ & 0.22 \\
\hline G allele & 479 & 263 & 45.1 & $1.0(-)$ & \\
\hline A allele & 141 & 85 & 39.7 & $1.25(0.84-1.87)$ & 0.12 \\
\hline \multicolumn{6}{|l|}{$-634 \mathrm{C} / \mathrm{G}$} \\
\hline $\mathrm{CC}$ & 147 & 76 & 48.3 & $1.0(-)$ & \\
\hline $\mathrm{CG}$ & 109 & 63 & 42.2 & $1.28(0.75-2.18)$ & 0.45 \\
\hline GG & 54 & 35 & 35.2 & $1.72(0.86-3.49)$ & 0.10 \\
\hline $\mathrm{C}$ allele & 403 & 219 & 46.7 & $1.0(-)$ & \\
\hline G allele & 217 & 129 & 38.7 & $1.38(0.98-1.97)$ & 0.06 \\
\hline
\end{tabular}

${ }^{a}$ Adjusted for gender, age, tumor histology, tumor stage, tumor size and metastasis. $\mathrm{P}<0.05$ was considered to indicate a statistically significant difference. VEGF, vascular endothelial growth factor; CI, confidence interval; -, no value.

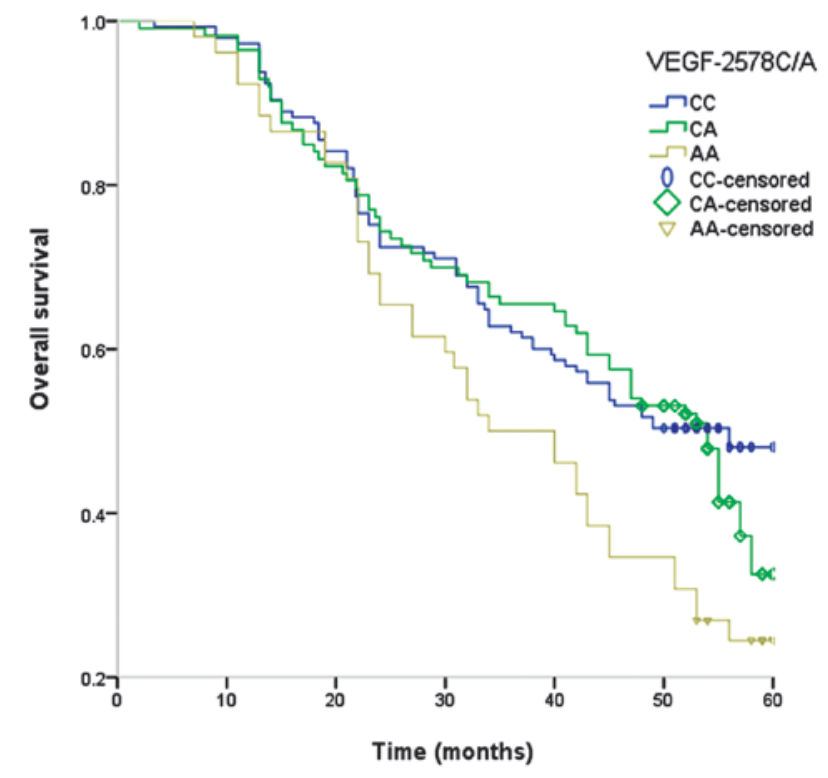

Figure 1. Kaplan-Meier curves of renal cell carcinoma overall survival stratified by various VEGF -2578A/C genotypes. VEGF, vascular endothelial growth factor.

Examination of Kaplan-Meier curves for the VEGF -2578A/C genotypes indicated that the VEGF $-2578 \mathrm{~A} / \mathrm{C}$ polymorphism is associated with the overall survival of RCC patients (Fig. 1).

\section{Discussion}

VEGF is involved in the regulation of angiogenesis and is considered to be a potent stimulatory cytokine in tumor angiogenesis, which appears to be key in influencing tumor metastasis and prognosis (21). Previous studies have indicated that polymorphisms in the VEGF gene are associated with various types of cancer, including breast, prostate and gastric cancer. VEGF gene polymorphisms are correlated with various characteristics of cancer, such as susceptibility, tumor grade and OS of cancer (22-24). Three gene polymorphisms, VEGF -2578C/A, -1154G/A and $-634 \mathrm{C} / \mathrm{G}$, located at the promoter region of $\mathrm{VEGF}$, are involved in altering the gene transcription and expression of VEGF (25). Few previous studies have investigated the association between VEGF $-2578 \mathrm{C} / \mathrm{A},-1154 \mathrm{G} / \mathrm{A}$ and $-634 \mathrm{C} / \mathrm{G}$ polymorphisms and the prognosis of RCC patients (17-19), thus, the present study is, to the best of our knowledge, the first to identify that the VEGF $-2578 \mathrm{C} / \mathrm{A}$ polymorphism is associated with the prognosis of RCC patients, as well as demonstrating an interaction with the tumor stage and size.

The present study identified that the VEGF -2578 AA genotype is associated with shorter OS period in RCC patients, indicating that the VEGF -2578 AA genotype increases the expression of VEGF and promotes tumor angiogenesis, thus resulting in a higher tumor stage and decreased OS in RCC patients. Therefore, VEGF gene polymorphisms 
may be critical in altering VEGF expression and influencing the progression of RCC patients. Furthermore, two previous studies reported results that were consistent with the present study, which demonstrated an association between VEGF gene polymorphisms and the prognosis of various diseases $(17,26)$. Hefler et al (27) reported that VEGF -634G/C, $-1154 \mathrm{G} / \mathrm{A}$, and $-2578 \mathrm{C} / \mathrm{A}$ polymorphisms were associated with increased VEGF expression and a shortened OS period in ovarian cancer patients (26). An additional study identified that the -2578 C allele was correlated with increased VEGF production in vitro (25). However, reports of an association between -2578C/A polymorphisms and tumor prognosis are inconsistent $(21,28,29)$. For example, Supic et al (30) conducted a study of 114 oral squamous cell carcinoma (OSCC) patients and 126 control subjects, and reported a non-significant association between VEGF -2578C/A polymorphisms and the prognosis of OSCC patients (29). The discrepancies between the above-mentioned studies may be due to differences in genetic variant frequencies between individuals with different ethnicities or carcinoma types.

Notably, the VEGF -634 GG genotype is associated with tumor size, although, no association was identified between the VEGF $-634 \mathrm{C} / \mathrm{G}$ polymorphism and the prognosis of RCC patients. One study indicated that the VEGF-634 GG genotype is associated with high serum VEGF levels and reduced OS periods in advanced gastric cancer patients when compared with the CC genotype (21). An additional study identified that the -634 CC genotype was significantly correlated with larger tumor size and higher histological grade (31).

The present study has two limitations. First, the study was conducted in a single hospital in China; thus, it may not be representative of the general population. However, the allele frequencies demonstrated Hardy-Weinberg equilibrium and were similar to the minor allele frequencies obtained from the The National Center for Biotechnology Information database (www.ncbi.nlm.nih.gov/SNP), which indicates that the population of the present study may be representative of the general population. Second, the number of cases analyzed in the present study was relatively small, which may reduce the statistical power to detect differences between the various VEGF allele groups. Therefore, further studies using a large multicenter cohort are required to investigate the association between VEGF gene polymorphisms and the prognosis of RCC patients.

In conclusion, the present study identified that the VEGF -2578C/A polymorphism may be associated with the prognosis of RCC patients, and may interact with the tumor stage and size. Therefore, the present study may aid with predicting the clinical outcome of RCC patients. Further large cohort studies are required to demonstrate the clinical significance of the VEGF -2578C/A polymorphism.

\section{References}

1. Jemal A, Siegel R, Ward E, et al: Cancer statistics, 2009. CA Cancer J Clin 59: 225-249, 2009.

2. Motzer RJ, Hutson TE, Tomczak P, et al: Overall survival and updated results for sunitinib compared with interferon alfa in patients with metastatic renal cell carcinoma. J Clin Oncol 27: 3584-3590, 2009.

3. Motzer RJ, Bander NH and Nanus DM: Renal-cell carcinoma. N Engl J Med 335: 865-875, 1996.
4. Cao Q, Wang J, Zhang M, et al: Genetic Variants in RKIP Are Associated with Clear Cell Renal Cell Carcinoma Risk in a Chinese Population. PLoS One 9: e109285, 2014.

5. Mu HJ, Zou J, Xie P, Xu ZQ, Ruan J, Yang SD and Yin Y: Association of leptin receptor Lys109Arg and Gln223Arg polymorphisms with increased risk of clear cell renal cell carcinoma. Asian Pac J Cancer Prev 15: 4211-4215, 2014.

6. Patard JJ, Pouessel D, Bensalah K and Culine S: Targeted therapy in renal cell carcinoma. World J Urol 26: 135-140, 2008.

7. Motzer RJ, Hutson TE, Tomczak P, et al: Sunitinib versus interferon alfa in metastatic renal-cell carcinoma. N Engl J Med 356: 115-124, 2007.

8. Vincenti V, Cassano C, Rocchi M and Persico G: Assignment of the vascular endothelial growth factor gene to human chromosome 6p21.3. Circulation 93: 1493-1495, 1996.

9. Watson CJ, Webb NJ, Bottomley MJ and Brenchley PE: Identification of polymorphisms within the vascular endothelial growth factor (VEGF) gene: correlation with variation in VEGF protein production. Cytokine 12: 1232-1235, 2000.

10. Koukourakis MI, Papazoglou D, Giatromanolaki A, et al: VEGF gene sequence variation defines VEGF gene expression status and angiogenic activity in non-small cell lung cancer. Lung Cancer 46: 293-298, 2004.

11. Luo T, Chen L, He P, et al: Vascular endothelial growth factor (VEGF) gene polymorphisms and breast cancer risk in a Chinese population. Asian Pac J Cancer Prev 14: 2433-2437, 2013.

12. Sivaprasad S, Govardhan B, Harithakrishna R, et al: Association of vascular endothelial growth factor (VEGF) gene polymorphism and increased serum VEGF concentration with pancreatic adenocarcinoma. Pancreatology 13: 267-272, 2013.

13. Mandal RK, Yadav SS, Panda AK and Khattri S: Vascular endothelial growth factor $936 \mathrm{c}>\mathrm{T}$ polymorphism increased oral cancer risk: evidence from a meta-analysis. Genet Test Mol Biomarkers 17: 543-547, 2013.

14. He D, Lu W, Chang K, et al: Vascular endothelial growth factor polymorphisms and risk of Alzheimer's disease: a meta-analysis. Gene 518: 296-302, 2013.

15. Garcia-Donas J, Rodriguez-Antona C and Jonasch E: Molecular markers to predict response to therapy. Semin Oncol 40: 444-458, 2013.

16. Vrdoljak E, Rini B, Schmidinger M, et al: Bisphosphonates and vascular endothelial growth factor-targeted drugs in the treatment of patients with renal cell carcinoma metastatic to bone. Anticancer Drugs 24: 431-440, 2013.

17. Jäkel CE, Hauser S, Rogenhofer S, et al: Clinical studies applying cytokine-induced killer cells for the treatment of renal cell carcinoma. Clin Dev Immunol 2012: 473245, 2012.

18. Kawai Y, Sakano S, Korenaga Y, Eguchi S and Naito K: Associations of single nucleotide polymorphisms in the vascular endothelial growth factor gene with the characteristics and prognosis of renal cell carcinomas. Eur Urol 52: 1147-1155, 2007

19. Sáenz-López P, Vazquez F, Cozar JM, et al: VEGF polymorphisms are not associated with an increased risk of developing renal cell carcinoma in Spanish population. Hum Immunol 74: 98-103, 2013.

20. Edge SB, Byrd DR, Compton CC, et al (eds): Kidney. In: AJCC Cancer Staging Manual. 7th edition. Springer, New York, NY, pp2010479-2010489, 2010

21. Abe A, Sato K, Habuchi T, et al: Single nucleotide polymorphisms in the 3' untranslated region of vascular endothelial growth factor gene in Japanese population with or without renal cell carcinoma. Tohoku J Exp Med 198: 181-190, 2002.

22. Salven P, Teerenhovi L and Joensuu H: A high pretreatment serum vascular endothelial growth factor concentration is associated with poor outcome in non-Hodgkin's lymphoma. Blood 90: 3167-3172, 1997.

23. Martinez-Fierro ML, Garza-Veloz I, Rojas-Martinez A, et al: Positive association between vascular endothelial growth factor (VEGF) -2578 C/A variant and prostate cancer. Cancer Biomark 13: 235-241, 2013.

24. Chen P, Zhu J, Liu DY, et al: Over-expression of survivin and VEGF in small-cell lung cancer may predict the poorer prognosis. Med Oncol 31: 775, 2014.

25. Oh SY, Kwon HC, Kim SH, et al: The relationship of vascular endothelial growth factor gene polymorphisms and clinical outcome in advanced gastric cancer patients treated with FOLFOX: VEGF polymorphism in gastric cancer. BMC Cancer 13: 43, 2013.

26. Absenger G, Szkandera J, Stotz M, et al: A common and functional gene variant in the vascular endothelial growth factor a predicts clinical outcome in early-stage breast cancer. Mol Carcinog 52 (Suppl 1): E96-E102, 2013. 
27. Hefler LA, Mustea A, Könsgen D, et al: Vascular endothelial growth factor gene polymorphisms are associated with prognosis in ovarian cancer. Clin Cancer Res 13: 898-901, 2007.

28. Shahbazi M, Fryer AA, Pravica V, et al: Vascular endothelial growth factor gene polymorphisms are associated with acute renal allograft rejection. J Am Soc Nephrol 13: 260-264, 2002.

29. Sa-Nguanraksa D, Chuangsuwanich T, Pongpruttipan T, et al: Vascular endothelial growth factor $-634 \mathrm{G} / \mathrm{C}$ polymorphism is associated with increased breast cancer risk and aggressiveness. Mol Med Rep 8: 1242-1250, 2013
30. Supic G, Jovic N, Zeljic K, Kozomara R and Magic Z: Association of VEGF-A genetic polymorphisms with cancer risk and survival in advanced-stage oral squamous cell carcinoma patients. Oral Oncol 48: 1171-1177, 2012.

31. Jin Q, Hemminki K, Enquist K, et al: Vascular endothelial growth factor polymorphisms in relation to breast cancer development and prognosis. Clin Cancer Res 11: 3647-3653, 2005 . 